Meta

Journal des tradlucteurs

Translators' Journal

\title{
The Importance of the Metacommunicative Purposes of Communication, or Teaching Students to Listen and Speak Like Normal Human Beings
}

\section{Sergio Viaggio}

Volume 50, numéro 1, mars 2005

Enseignement de la traduction dans le monde

Teaching Translation Throughout the World

URI : https://id.erudit.org/iderudit/010659ar

DOI : https://doi.org/10.7202/010659ar

Aller au sommaire du numéro

Éditeur(s)

Les Presses de l'Université de Montréal

ISSN

0026-0452 (imprimé)

1492-1421 (numérique)

Découvrir la revue

Citer cet article

Viaggio, S. (2005). The Importance of the Metacommunicative Purposes of Communication, or Teaching Students to Listen and Speak Like Normal Human

Beings. Meta, 50(1), 78-95. https://doi.org/10.7202/010659ar
Résumé de l'article

Les énoncés s'inscrivent toujours dans un environnement social spécifique ; ils sont produits et compris en fonction de certains objectifs métacommunicatifs. La communication dépasse le simple échange d'énoncés : la vraie compréhension va au-delà des signes linguistiques, recherche la pertinence pour atteindre le sens cognitif et pragmatique latent. Si les étudiants ne sont pas sensibilisés à privilégier le sens dans la compréhension et la réexpression, ils courent le risque de comprendre, de mémoriser et de restructurer de manière parcellaire. 


\title{
The Importance of the Metacommunicative Purposes of Communication, or Teaching Students to Listen and Speak Like Normal Human Beings
}

\author{
SERGIO VIAGGIO \\ United Nations, Vienna, Austria \\ Sergio.Viaggio@unvienna.org
}

\begin{abstract}
RÉSUMÉ
Les énoncés s'inscrivent toujours dans un environnement social spécifique; ils sont produits et compris en fonction de certains objectifs métacommunicatifs. La communication dépasse le simple échange d'énoncés: la vraie compréhension va au-delà des signes linguistiques, recherche la pertinence pour atteindre le sens cognitif et pragmatique latent. Si les étudiants ne sont pas sensibilisés à privilégier le sens dans la compréhension et la réexpression, ils courent le risque de comprendre, de mémoriser et de restructurer de manière parcellaire.
\end{abstract}

\section{ABSTRACT}

This article submits that utterances are always uttered in a specific social context and are produced and understood out of specific metacommunicative purposes. There is more to communication than the exchange of propositions. Real comprehension is always topdown and relevance-governed, and succeeds at the level of metarepresented cognitive and pragmatic meaning. If students are not taught to understand and speak meaningfully, they fall into the trap of modular comprehension, memorization and verbalization.

\section{MOTS-CLÉS/KEYWORDS}

top-down processing, metarepresentation, critical listening and speaking, relevance, cognitive and qualitative effects

I think that one of the great mistakes that an interpretation (or, for that matter, translation) teacher can make is to forget completely about the social embedding of communication. To my mind, students should never be asked to interpret as if in a social vacuum. The first thing to be taught, I am convinced, is a realistic and comprehensive model of communication. In my experience, my development of García Landa's proves extremely useful. Let me explain it succinctly.

According to García Landa (2000), speech production and comprehension consist in the mutual production of speech percepts $(L P s)^{1}$ that, for simplicity's sake, can be described as a composite of noetic meaning (expressible in propositional terms) and linguistic signs. A speech act is initiated as an intended speech percept (LPI) comes to the speaker's mind as a result of the simultaneous activation of the linguistic systems that he has internalized and of specific chunks of his knowledge of the world as stored in his memory. In order to have an interlocutor perceive it in turn, the speaker generates a sensorially perceptible stimulus consisting of an utterance (that, add $\mathrm{I}$, is paralinguistically and kinetically configured). As the interlocutor applies to 
this semiotic stimulus his own interpretation rules activating a representation of the speaker's linguistic systems and specific chunks of his knowledge of the world, a comprehended percept $(L P C)$ is produced in his mind. The speech act is produced in a specific social situation upon which gravitate the participants' personal experience, social practices and, generally speaking, culture, plus a situation-specific microworld (the relevant collection of schemata, frames, scenes and scenarios). If the speaker's intended percept and that produced by the interlocutor are identical - or, in simpler terms, if they share the same noetic content, i.e. if meaning as intended by the speaker is the same as meaning as comprehended by his interlocutor, communication has succeeded.

To my mind, however, this is the short, but not the long of the story. A speaker must have a motivation to speak. This motivation will govern his specific main and constellation of secondary pragmatic intentions, which, in turn, will govern his meaning meant and what he actually ends up saying. And an interlocutor too must have a motivation to understand. This motivation will govern his specific main and constellation of secondary expectations, which, in turn, will govern what he actually ends up understanding. Understanding will, moreover, produce specific contextual effects upon him, both cognitive and emotive or qualitative - which will now determine his attitude both to what has been said and to what comes next.

The motivation to speak or to understand, moreover, does not simply boil down to producing a string of intended or comprehended "mini" LPs (equivalent to units of sense), processed bottom-up, or, even, a complex perceptual space that is the result of their further, immediate top-down processing, but, rather, to produce, on that basis, a series of relevant metarepresentations. In that sense, there is, at the postperceptual macro level, a difference in degrees of comprehension both in quantitative and qualitative terms, i.e. in how much you understand bottom-up at the micro level, and how relevant is that which you have or have not understood. This difference in quantitative and qualitative degrees of bottom-up comprehension in the end is decisive when it comes to metarepresenting top-down the speaker's global communicative and metacommunicative intentions. If at the micro level, due to the linearity of speech, comprehension is also linear (though more discretely segmented), at the postperceptual level, comprehension entails a thorough reorganization and systematization of those linearly produced LPCs: Understanding this paper, for instance, does not amount to having produced a sequence of LPCs as a result of having linearly processed every clause. At the macro level - and this is crucial - relevant identity of meaning meant and understood is a matter of degree. Our comprehension of what we are told is not, therefore, simply the sum total of a longitudinal series of LPCs produced in a longitudinal series of speech acts: We constantly enrich and revise our global representation of what that linear series of LPCs - presumably, but not always necessarily identical to the respective LPIs - amount to as meaning meant on the part of our interlocutor. At the neurophysiological level, it seems quite clear: If a 250-millisecond LPC (say, the clause you have just read) seldom makes it past short-term memory, an immediate top-down speech perceptual space (say, what I have been saying for the last few lines) seldom makes it past medium-term memory: Only metarepresentations are stored in long-term memory (say, my argument so far). At the macro level, I insist, the identity between meaning meant and understood is a matter of degree. In other words, we have two different layers of noetic comprehension: the 
one that is the object of the speech perception proper, and a more complex one that is the product of a (series of) metarepresentation(s) based upon it. The corollary is that, according to your particular purpose at a given time, your perception of my meaning meant may not be the relevant one at the postperceptual level (i.e. you have misunderstood relevant LPIs or wasted unnecessary time and effort understanding less relevant or totally irrelevant ones - or, worse, your metarepresentation based on a perfect spontaneous, on-line understanding of my utterance is completely off the mark). This, as I hope to prove, is fraught with momentous theoretical and practical consequences for mediation.

There is a qualitative leap, moreover, between understanding what people say and understanding people - what they mean to say, indeed, but also what they mean to hide, why, etc. This second-degree comprehension, of course, goes far beyond spontaneous, immediate comprehension of officially intended noetic meaning. The consequences for mediation are, again, decisive. What leaves the mnesic trace, in Seleskovitch's felicitous expression, is, precisely, metarepresented meaning, since it alone can give rise to further, more complex metarepresentations through propositional enrichment. Our memories of past speech acts - and that should be, but often is not, the case with consecutive interpreters - are indeed almost entirely reduced to metarepresented noetic content - and so should the interpreter's memory of the speaker's meaning meant. Indeed, the fact that noetic content can be reverbalized without much ado is essential for translation and interpretation. The translation of pragmatic texts, as a case in point is mostly a matter of reproducing noetic content. This is what Reiss and Vermeer (1991) imply when they speak of a text as an information offer (which, rigorously speaking it is not: a text is nothing but frozen speech; nor does it offer anything at all - only people can offer information or, for that matter, anything else).

In any event, the basic problem remains: i.e. that of the quantitative and qualitative number of cases of mini-LPI/LPC identity that is ultimately necessary, sufficient or optimum for the specific metacommunicative purposes and stakes in hand. What counts, then, is that LPI/LPC identity (including the intended metarepresentations) obtains relevantly in the end: This is the fact that allows for the mediator's manipulation of propositional content and semantic form while nevertheless ensuring relevant identity of meaning meant and comprehended.

It is also a fact that, through an ulterior process on the basis of speech comprehension, a keener interlocutor may well metarepresent what a speaker means better than another or than the speaker himself. It happens all the time; in some situations some people are more adept at understanding their interlocutors than the latter themselves - it is systematically the case between grownups and young children. Indeed, mediators should have such skills as a crucial part of their professional wherewithal. Again, if what I want to say to you and your comprehension of it do not totally overlap, what really counts is that they both coincide in whatever aspects or features are mutually or even individually relevant - i.e. that they are identical enough: enough for the metacommunicative purposes in hand, for the specific social stakes. What matters, in the end, is not sheer noetic identity, but what the interlocutors have achieved by means of such identity, however partial or imperfect. In this particular case, it is not enough for me that you understand every bit of the noetic content I am so labouriously verbalizing - what counts is that you understand it (it, not something 
similar or equivalent or analogous to it) in a certain way, that comprehension of what I mean you to understand produces certain effects and, most especially, that it does not produce certain others.

As I verbalize this series of LPIs as they come into my awareness more or less every 250 milliseconds, I do so striving to convince you, and trying not be boring or not to make you work more than you have to; and I do hope that, even if I cannot convince you, at least you will cast a benign eye on my point, suspend disbelief and be willing to entertain it as yours for a while before passing final judgement on it i.e. before you decide what to do with what you have understood. All this is drenched in emotion. This fact is very much relevant to me as a speaker, and I am sure that whether you are or not convinced, and entertained, irritated or bored in the process, is equally relevant to you as an interlocutor. Is this or is this not a relevant feature of our communication? (Isn't this, i.e. what happens to us as a result of comprehension, what the success of literary speech acts is all about?) This is, in the end, the paramount concern of any flesh-and-blood human being, whether translating or not: what it feels like, not what it actually is or the way it is perceived - much as what it feels like is ultimately determined by what actually is and the way it is perceived.

\section{There is more to meaning than propositional content}

There are many other layers of meaning that travel between speaker and interlocutor, even though they are not part of the speech perception proper and ensue from noetic comprehension. A model of communication through speech cannot leave out the meaning of silence. True, silence is not a part of the utterance, but can be nevertheless meaning-laden. Very often, what is not being said is also an important part of what we understand, or, rather, of what we end up understanding after we have understood what has actually been said "officially." Silence is interpreted via a metarepresentation of what is being left unsaid and a meta-metarepresentation of why it is left unsaid. A model of communication through speech, moreover, can neither ignore the metarepresentation of what might have been said instead of what has been actually uttered: the fact that a wife says to her husband "I'm fond of you" rather than "I love you" may be heavily loaded - and certainly no less the fact that she does not say anything at all. And equally loaded may be the fact that at an international gathering a Spanish delegate of Catalan origin intervenes in French rather than Spanish. Silence, as well as some - statistically very rare - lexical and other positive choices, becomes relevant, in other words, insofar as an interlocutor can metarepresent the alternatives and the significance of the fact that they have not been chosen or, even, that they have been consciously discarded. Because that is very much a part of meaning meant - if meant indirectly - or, if not meant at all, then of meaning as comprehended by the interlocutor despite the speaker's intentions. Again, this is fraught with consequences for mediation, since the specific weight of an utterance - especially its semantic form - may be more, or less, relevant as a positive choice. As I was writing an earlier version of this piece, China and the US were at diplomatic loggerheads over the fact that a Chinese Mig had crashed in mid air with an American intelligence plane above the China Sea, as a result of which the Chinese pilot was missing and presumed dead, whilst the American plane was forced to perform an emergency landing on a Chinese island. All the fuss was over whether 
the American aircraft was a "spy" plane (as characterized by the more independent Euronews), or a "surveillance" plane (as labelled by the more obsequious BBC) legally ogling from afar. In this specific context the semantic difference between an "apology," which was what the Chinese demanded, and an "expression of regret," which was as far as the Americans were ready to go, are not interchangeable: they give rise to relevantly different (even contradictory) politically charged metarepresentations. In most other contexts, instead, they would be very much interchangeable: "I'm sorry that your father is so ill, Peter" will not give Peter much food for metarepresentational lucubrations about whether I said "I'm sorry" rather than "I regret" in order to convey that I feel responsible. Pretending that every speaker chooses his words as an embattled Minister about to lose a no-confidence vote, carefully weighing and then rejecting each and every alternative (which, by the way, is impossible), and that, therefore, every word present counts as much as every absent word, is as preposterous in direct communication as it is damaging when it comes to the notion of fidelity in interlingual mediation.

As we can see, the motivations and intentions that bring together the interlocutors - i.e. that give rise to the speech act to begin with - are an important part of the totality of human communication that transcends speech production and comprehension. Again, the ultimate, metacommunicative, purpose of communication is not simply to produce speech perceptions in our interlocutors, but to achieve certain goals thereby - nor is it purely to perceive what others have to say to us, but also to achieve certain goals thereby. What I am trying to bring in explicitly is that we are not simply after understanding the other person's speech, we also want to understand his motives and metarepresent all that he may be willing to convey to (and/or hide from) us by producing a series of LPIs - and this we do on the basis of our own emotively-laden motivations. If a mediator does not take stock of why and what for the interlocutors who engage him have themselves engaged in producing speech perceptions in each other, he may be able to "translate" most competently, but he cannot possibly mediate effectively - or, at least, optimally. Because what he must see to is not ensuring sheer LPIo/LPCi identity, whatever the ulterior social consequences, but rather ensuring a situationally relevant identity, coincidence or overlapping of metarepresented meaning that will be also as pragmatically adequate as circumstances demand, advise or allow.

Direct communication can indeed be modelled short of the motivations and intentions that govern it on either side, and of the effects that comprehension produces. When dealing not with one but with two speech acts, however, it is impossible to extricate the mediator's overall subjectivity as both an interlocutor to the speaker and speaker to the new interlocutors, because it is there in the very middle of both acts. No matter how hard he may try, the mediator cannot possibly reverbalize the speaker's LPI exactly as he himself has understood it - he must of necessity modify at least parts of its perspective (as García Landa points out, sense never travels along a straight line, it is refracted by the social gravitational field). The question, then, is not whether but how he is adequately to choose this new perspective. And he cannot possibly unless he takes stock of the metacommunicative purpose both of the original speech act and of his own, which may be a very different one indeed (hail, after all, skopostheorie!). As a case in point, even though the BBC announcer has informed that an American "surveillance" plane has just "collided" with a Chinese fighter and 
that a "major crisis is imminent," I'll call up a friend and tell him that I have just heard that an American "spy" plane has "crashed" with a Chinese fighter and that "there's bound to be big trouble" - for me the semantic subtlety is totally irrelevant: A spy plane by any other name will smell as rotten, whilst a "collision" will be as loud as a "crash" and an "imminent crisis" means, precisely, that "we're in for some big trouble." But, on the other hand, if I were mediating professionally, even though I would not bend backwards to say "collided" rather than "crashed," I would be caught dead interpreting "surveillance" as "spy" - or vice versa - at a meeting of the UN Security Council! One word was not, but the other indeed was chosen in order to produce (or, rather, not to produce) a certain metarepresentation. For purely pragmatic reasons, I would not normally say "big trouble" for "crisis" either: The less formal phrase would connote a less "serious" approach by the speaker - but the difference here is that the speaker would not have chosen to say "crisis" in order not to say "big trouble." I would not make much of an effort, instead, to say "imminent" rather than "impending." As we can see, what mostly matters is not to produce a certain effect, but the status of each choice is different in the original, whereby the mediator would be inept if he assessed them similarly.

The whole of a speech act (and much more so a complex series of speech acts), moreover, is governed by relevance - if enlarged so as to encompass also the noncognitive contextual effects of comprehension. Even as it stands, relevance theory is, by definition, larger than speech-production and comprehension theory, and much more so than translation theory. As I hope to show, only relevance theory can help assess quality in communication (both direct and mediated, monolingual or interlingual). Relevance theory alone can account for the pragmatic and even noetic degree of success in communication, i.e. for whether the degree of noetic-meaning identity is barely "enough" or optimum or somewhere in between for the metacommunicative purposes and stakes in hand.

As a direct consequence of all of the above, a mediator is very much responsible for both the noetic and pragmatic success of communication: The last thing he should do is wash his hands of it (even if the moment often comes when he has no alternative, this is a fallback position that should never be his default strategy). In this respect, I am afraid I cannot agree with any dictum to the effect that a translator just "translates," that, paraphrasing Tennyson, "His is not to reason why, his is but to do... and bye!" This is not the way I understand the translator's freedom, or, for that matter, that of any other human being. We are always responsible for the consequences of our actions; whilst, as professionals, we are deontologically liable for the consequences of our professional actions.

In view of the inescapable asymmetry between the ability, motivations, intentions and interests of any pair of interlocutors, metacommunicative purposes can radically vary from the first speech act to the second as a function of the mediator's assessment of what counts as relevant identity this second time around, by which I mean the necessary - from sufficient to optimum to total - degree of perceptual identity between meaning meant and meaning comprehended together with an apt from sufficient to optimum - correlation between effects pursued and achieved for the metacommunicative purposes at stake. If human communication as a whole is inseparable a) from the motivations, intentions, interests, intelligence and sensitivity of all direct and indirect interlocutors and participants or stakeholders in a given 
event (including the mediator himself and any relevant third parties) and b) from the effects that comprehension produces on subjects, then mediation - whether interlingual or not - cannot be invariably limited to reverbalizing a speaker's "official" meaning meant.

Indeed, understanding what I am saying is... understanding what I am saying. If I am irrelevant, or awkward, or uncouth, or simply stupid, that's my and my interlocutor's problem. There is no one in the middle to help us achieve what we cannot achieve on our own. As initiator of this act of speech, for instance, I assume full responsibility for what I want to say or hide, and how and when to say it. And you, dear reader, assume full responsibility for cooperating with me. Our success is in nobody's hands but our own.

But the moment responsibility for your understanding me relevantly is not yours alone but a professional mediator's, and the moment making myself relevantly understood by you is no longer my exclusive responsibility but also that of a professional mediator, then you and I are both entitled to demand of him his best professional effort. We are entitled to expect that he understand the reasons behind my initiating this speech act (and not only what I am officially trying to say in it) better than you (and maybe even than I) can, and that he communicate more effectively than I - even if the specific rule of the specific game is to convey nothing but meaning as officially meant (which happens only in the most rarefied, severely institutionalized social settings). And it is also his responsibility to understand the reasons why you choose to participate in this speech act better than I (or maybe than you yourself) can. That is what turns a "mere" translator into a fully fledged mediator: his ability to understand beyond meanings officially meant (regardless of what he actually does with that understanding). A general theory of mediation of necessity must explain that the role of the mediator is, precisely, modulating - or, if you prefer, manipulating meanings as officially meant in order to help communication overcome all manner of hermeneutic and pragmatic barriers in order to serve its metacommunicative purpose.

\section{My development of García Landa's model of verbal communication}

It reads as follows (do not be daunted by the symbolic shorthand - that is all that it purports to be):

1) Every more or less complex successful act of speech $D$ (whether oral $V$, written $T$, or interiorized $I$ ) in a given language $o$ is a social transaction whereby someone (the subject of production), out of a conscious motivation $W$, governed by an adequate unconscious predisposition to cooperate $Z$, with a main pragmatic intention $Y$ and secondary pragmatic intentions $y$, communicates a propositionally more or less complex speech percept intended $L P I$ which is a function of the activation of a given set of linguistic systems $o$ together with a set of pre-comprehension schemes, knowledge base or passing theories $K$.

2) To that effect, he sets in motion a complex mental operation which involves mainly constructing and presenting to his interlocutor(s) a finished social product which is a sign chain $F$ in that language $o$. Such chain consists of a) a phonomorphosyntactic structure $X$ (actualizing a certain phonomorphosemantic system $L$ ), b) a semantic potential $S$ (actualizing a semantic system $H$ ), c) a rhythmicoprosodic structure $V$ (actualizing a rhythmicoprosodic system $R$ ), and d) a register $J$ (from a 
register series $Q^{2}$ ). This chain is also necessarily couched in a series of suprasegmental (paralinguistic or typographical) features $C$, and kinetic or graphic features $E$ that reinforce, refine or modify its meaning. (In face-to-face and written communication, then, the stimulus triggering the comprehension process consists of three components: $F, C$ and $E$, although the latter one is lost in strictly acoustical communications such as radio, telephone, etc., often making comprehension more difficult.) All the above components are characterized by specific sets of features $m, n$, etc.

3) The speech act is carried out in a given social situation or sociohistorical field $G$ governed by a shared system of beliefs, norms and practices, or a certain shared life and personal experience $P$, within a given microworld $M$, at a historic moment $V H$, and, within that moment, at a specific time $t$. (All these components are also characterized by specific sets of features $m, n$, etc.)

4) A subject of comprehension (interlocutor, observer, or the very speaker engaged in an inner dialogue with himself) listens and understands in a complex mental operation which results in his producing in turn a speech percept comprehended $L P C$, itself a function of the activation of a representation of the same linguistic systems $o$ and knowledge base $K$. In order to do so, he must resort to or overcome his conscious motivation or resistance $U$ and be governed in turn by an adequate unconscious predisposition to cooperate $Z$. We should stress the active nature of comprehension, whereby the comprehender (re-)constructs his speech perception of the speaker's meaning meant retro-applying his own filters $U, Z$ and $K$ to the acoustic/optic stimulus FCE. Comprehension produces, moreover, main and secondary contextual effects $A a$ (cognitive or qualitative), which, in order for communication not to have failed pragmatically, must correlate somehow to the consciously or unconsciously intended effects.

Regardless of its pragmatic success, noetic communication will have succeeded in so far as, in a given social situation, perceptual identity $(=)$ is achieved between what the speaker wants to convey $(L P I)$ and what the comprehender has understood $(L P C)$ - otherwise it will have failed to a greater or lesser degree. Since neither perception is open to observation, such identity is often impossible to verify empirically: it can only be postulated. What is crucial to retain is that, in the end, this identity is a function of the relevant linguistic (LHRQ) and cognitive (KPM) baggage - the hermeneutic package - shared by both parties to an act of speech and of how adequately predisposed they are to communicate with each other $(Z)$. In order to have succeeded pragmatically and, moreover, qualitatively, however, the result of communication must be relevant perceptual identity $([=])$ between $L P I$ and $L P C$ - i.e. as apt a balance or correlation as necessary - from sufficient to optimum - of identity of meaning and correspondence of contextual effects intended and achieved. It is worth stressing that in expressive - and most especially literary - speech, mutual orientedness entails emotive empathy, a kind of shared emotive package that would be the emotive counterpart of the cognitive hermeneutic package. If this empathy is absent, for instance, the reader will understand the poem but fail to be affected by it in the way the poet presumably intended ${ }^{3}$.

In symbolic notation, the model looks as follows:

$$
\text { Do: }>Y y>L P I^{K} o \rightarrow\left[F o\left(X m^{L}, S m^{H}, V m^{R}, J m^{Q}\right) C m E m\right] G^{P M} V H t m \leftrightarrow U^{Z}>L P C^{K} O \rightarrow A a
$$


And pragmatically successful communication will have obtained if:

$\left(L P I^{K} O[=] L P C^{K} O\right) G^{P M} V H t m$

Or, even more laconically:

$L P I[=] L P C$

We could add that communication will have succeeded pragmatically if, in the specific situation $G^{P M}$, pragmatic intentions adequately correlate with the contextual effects achieved; i.e. if:

$Y y=A a$

So that communication will have globally succeeded at both the noetic and pragmatic levels if there obtain both perceptual identity and an adequate correlation of the contextual effects pursued and achieved:

$Y y>L P I o=L P C o \rightarrow A a$

It is worth pointing out that pragmatic intentions govern an LPI, but do not actually produce it, whilst comprehension - i.e. $L P C$ - does produce all contextual effects $A a$. In this respect, may I clarify that the same symbol 'stands, as the case may be, for perceptual identity and adequate correlation between contextual effects pursued and achieved - what, for the sake of brevity, we might call pragmatic correspondence. Globally perfect communication would lie, then, in an optimum correspondence between motivations, interests, intentions and contextual effects coupled to an absolute identity of intended and comprehended sense. As with every human endeavour, of course, perfect communication does not exist: We must make do with a socially relevant degree of success, i.e. with being able to communicate closely enough to this unreachable ideal. In actual reality, what we pursue and normally manage is something both less ambitious and more practical: not total LPIo/LPCo identity and perfect $Y y / A a$ correspondence, but sufficient identity and acceptable correspondence, in other words, what I call relevant identity between meaning as meant and meaning as comprehended.

Obviously, the degree of identity and threshold of acceptability varies for each specific act and, more generally, for each specific type of situation. In this respect, a typology of situations is the real phenomenon behind a typology of texts.

\section{The model of interlingual mediation}

We simply have two successive speech acts in different languages:

$$
\begin{aligned}
& W^{Z}>Y y>L P I^{K} o \rightarrow\left[\mathrm{Fo}\left(X m^{L}, S m^{H}, V m^{R}, J m^{Q}\right) \mathrm{CmEm}\right] G^{P M} V H t m \leftrightarrow U^{Z}>L P C^{K} o \rightarrow A a[\rightarrow] \\
& {[6] W^{Z}>Y y>L P I^{K} o \rightarrow\left[\mathrm{Fo}\left(X n^{L}, S n^{H}, V n^{R}, J n^{Q}\right) C n E n\right] G^{P M} V H t m+n \leftrightarrow U^{Z}>L P C^{K} o \rightarrow A a} \\
& D i
\end{aligned}
$$

Where the symbol $[\rightarrow]$ stands for the adaptation that the mediator, bringing his subjectivity professionally and deontologically to the fore (if not necessarily overtly, of course), operates between LPCo and LPI i i.e. between what he has understood and what he now means to convey. Mediation succeeds, then, if, within a given objective 
situation influenced by subjective emotional and cognitive factors, relevant identity [ $=]$ is established between what the speaker wishes to convey and what the mediator's interlocutor understands:

LPIo $[=] L P C i$

The subtype of homoscopic homofunctional mediation succeeds if:

Yy $>$ LPIo [ $=] \mathrm{LPCi} \rightarrow \mathrm{Aa}$

Which means that there is both perceptual LPIo/LPCi identity and an adequate (i.e. the best possible under the circumstances) degree of pragmatic correspondence between the original speaker's pragmatic intentions and the contextual effects of comprehension on the mediator's interlocutor. A mediator, however, can strive for pragmatic correspondence through non-translation:

$Y y>(L P I o \neq L P C i) \rightarrow A a$

In this specific case, there is no LPIo/LPCo identity (i.e. their propositional content is totally different), but nevertheless relevant effects are achieved. This is the model normally applicable, for instance, to the "translation" of jokes, when the mediator substitutes the speaker's with his own. And it can pursue, of course, many other goals, even the most unidiomatic literality or maximum possible equivalence at any formal level. It all depends on the mediator's skopos. The mediator's assessment of his skopos is his first professional judgement and, as such, open to professional and deontological criticism. It is, therefore, also the first thing that ought to be assessed when judging professional performance at any level: First comes an evaluation of how apt is the assessment of what counts as relevant identity under the circumstances. Only then does it make sense to evaluate how aptly it has been carried out in practice.

\section{The centrifugal claims on the mediator's loyalty}

Loyalty is the compass that allows a mediator to chart his strategic course. Specifically, loyalty will help him establish what counts as relevant LPIo/LPCi under the specific circumstances. Basically, a mediator's loyalty, like that of any other professional, is owed first and foremost to his profession. Professional deontology governs all ethical and technical options down the line. Within this supreme loyalty, and again like with any other professional, a mediator's loyalty is owed to whoever hires his services. A mediator may be recruited by the speaker, his interlocutor(s)/reader(s) or a third party. The latter is normally the case. There is, however, a difference between paying the piper and calling the tune. The mediator's loyalty to the profession - and through it, to society at large - poses its own, I submit, supreme imperative to uphold, foster and develop ever more scientific professional norms.

\section{Relevance to the left, relevance at the centre and relevance to the right}

Indeed, for every mediator, relevance spills over both ends of the speech act. To begin with, he is to attend to the metacommunicative framework: to the speaker's motivations and intentions (including outright reluctance), and to the predisposition or resistence to understand on the part of the interlocutor, including, needless to say, the effects that comprehension may have upon him. His most delicate analysis must 
start on the left of the DVo. The interpreter must, of course, query what the speaker is saying "officially" (i.e. understand his LPIo). But it is essential as well that he constantly ask himself what the speaker is doing or, rather, trying to do by saying what he is saying, as well as why, what for, and how well he is managing.

The analysis of $W^{Z}>Y y$, however, is not enough. True, in principle the interpreter is paid (or, rather, those who pay him usually believe it to be the case) to reproduce an LPIo, i.e. meaning as officially meant - not to detect the reasons behind it. His basic, specific task is, indeed, to understand what the speaker is actually saying (or, rather, meaning to say), i.e. the central part of the model. At that moment, Fo, and especially its semantic form, plays its crucial role as a verbalization of the LPIo - as its only linguistic evidence (which, again, may be corroborated, qualified, enriched or belied by the paralinguistic and kinetic configuration). Since the semantic form mostly overrides all others, it lays the more dangerous trap. The mediator should constantly remember that semantic "content" is but the semantic form of propositional content. He should remember that it is the LPIo he is after - which, indeed, he can only or mainly access on the basis of the relevant semantic representation, but which largely transcends it. What matters, in other words, is not the semantic form of propositional content, but noetic content itself.

For many, here the problem would seem to be solved: The interpreter has understood the speaker's motivation, intention and meaning meant (i.e. he has managed relevant LPIo/LPCo identity, even though he is not the speaker's intended addressee), and has presumably managed to reverbalize his LPIi through a faultless Fi. Well, not quite: there remain a couple of hurdles to negotiate. For starters, we have the often neglected paralinguistic and kinetic configuration of the interpreter's utterance that which we normally call the interpreter's "presence" or "presentation," i.e. his ability to speak, to produce adequate speech acts, which is the oral mediator's counterpart to the translator's textual competence. This ability entails, of course, the ability to express himself correctly, precisely and clearly in the right register and, therefore, to reproduce different registers, but, also, the ability relevantly to reproduce, if need be, all manner of mistakes. But there is more to it: Each and every component of expression can and should be attended to and practised separately. All too often in interpreting classes $C$ is neglected, even though it is probably the single most decisive factor when it comes to the naturalness, intelligibility and, therefore, acceptability of an interpretation.

Fine. Let us assume that our student has overcome all those obstacles. So far he has travelled the following distance:

$$
W^{Z}>Y y>L P I^{K} O \rightarrow\left[\mathrm{Fo}\left(X m^{L}, S^{H}, V m^{R}, J m^{Q}\right) C m E m\right] G^{P M} V H t m \leftrightarrow U^{Z}>L P C^{K} o 6 A a[\rightarrow]
$$
DVo

$$
[\rightarrow] W^{Z}>Y y>L P I^{K} i \rightarrow\left[F i\left(X n^{L}, S n^{H}, V n^{R}, J n^{Q}\right) C n E n\right] \ldots
$$
DVi

So far, in other words, the left and the centre of the mediating bridge have been negotiated.

On the right-hand end, the interpreter must analyse his own interlocutor's attitude and the effect that the speaker is having on him through the interpretation, i.e. how the interlocutor is understanding, how much he is cooperating and why. Neglecting 
the speaker's motivations and intentions (which are, however, the first thing we pay attention to in our own daily exchanges whenever anybody - and most especially a stranger - addresses us) leads to not understanding Fo as the initiation of a speech act by someone specific, out of a specific motivation, with a specific intention, here and now. Neglecting the interlocutor's disposition (or reluctance) to cooperate, his ability to understand, and the effects that comprehension is having or is likely to have upon him (which, however, is the first thing we take into account in our daily exchanges whenever we address anybody - and most specially a stranger) leads to not understanding Fo as the initiation of a specific speech act addressed to someone specific, who also has a specific motivation and intention, here and now.

It is not a matter of the interpreter pondering only at this stage his interlocutor's "culture" or "idiosyncrasy": this is something that we will have taught each student to assess together with the speaker's motivation and intentions. But he must also take stock of the social stakes and, especially, of any possible mismatches at the K level. He must also assess the interlocutor's attitude and, ultimately, determine what counts as relevant identity for him, in order, on that basis, to come up with the aptest FiCnEn possible. Out of such an analysis, then, he will adopt his mediating strategy and choose his tactic options, giving unavoidable precedence to some participants over others: at a court of law, the accused, the judge, the defending lawyer, the prosecutor, the verbatim reporter, the security guards, each member of the jury, the public and the journalists are listening with different ears; in the conference room the interpreter's Fi also meets different abilities and dispositions to understand. Not all of them have equal social weight in the specific situation, and it behoves the mediator to determine which one or which ones count for the purposes of relevant LPIo/LPCi identity.

Let me stress the rhetorical and social importance of $C$ - and, in the case of dialogue and consecutive interpretation, $E$ - which is also decisive when it comes to get the message across, to achieve relevant LPIi/LPCi identity. In view of the decisive function of all factors, including paralinguistic and kinetics, around utterances proper (which, by the way, tend to be defective), the latter cannot but lose some of their specific weight. This is clearly seen in the model, where $F$ has a role both central and relative.

\section{Oral "texts" too can be instrumental or documentary}

Proponents of absolute, come-what-may "fidelity" to "what the speaker says" represent the sourcierist camp of the profession: those who maintain that the interpreter is invariably the speaker's alter ego and cannot be anything but the speaker's alter ego; since if the speaker has chosen to say or not to say in this or that way "there must be a good reason," and who is the interpreter anyway to decide otherwise. As if each time a speaker opened his mouth to be interpreted he delicately and cunningly weighed every word, however awkward, inept or mistaken. As if, even in that case, the possibly different relevance and acceptability criteria by his new interlocutors did not count in the least. As if the speaker's very motivations and pragmatic intentions were of no concern. As if, in the case of oral mediation, "words" counted more than anything else. It seems incredible that sourcierists, who are fewer and fewer in literary translation and have all but disappeared among pragmatic translators, still seem to constitute the overwhelming and vociferous majority among interpreters, especially 
simultaneous 4 . If in translation we admit skopostheorie without much tremor, why should it be a cause of dismay or dread in oral mediation, especially in simultaneous interpretation, in which neurophysiological limitations - let alone dialectal or foreign accents, unusual social or professional lects, mangled utterances, etc. - more often than not prevent any attempt at completeness, no matter how desirable? In relevance-theoretical terms, why should interpretive use ${ }^{5}$ be the only alternative? What is in principle the problem with "translating" an expert's awkward explanation at a seminar as descriptively as written instructions are normally translated for their users?

I cannot quote relevant statistics, I am afraid, but I dare venture to say that the number of oral utterances with documentary value is infinitesimal - even though they are undoubtedly more rife in the more structured and official situations in which the presence of a mediator is typically required. But even then, we do not speak to bequeath an eternal record of exactly what we have said and how exactly we have spoken. As a matter of fact, for that we normally write. The immediacy or oral mediation, on the other hand, with the physical co-presence of speaker, mediator, and interlocutors brings in most fully such a key pragmatic factor as face everybody's and, most notably, that of the interpreter himself. (The face of the unknown and absent author of the tourist brochure is of no consequence - nor, for that matter, is Shakespeare's.) In oral mediation, to boot, power or tenor also take a front seat. In other words, social relations appear at their rawest.

These differences in the social situation affect, no doubt, the criteria determining what counts as relevant identity between intended and comprehended meaning. An oral mediator must decide which strategy is best or more advisable at each step. Averring that oral mediation must be always documentary is, as any assertion based on prejudice and not on a scientific analysis, a superstition.

And yet it should be enough to watch any good consecutive interpreter at work in order to understand that a good interpretation is almost always instrumental: Without the immediacy of the reply still resounding in medium-term memory, without the pressure of the speaker's parallel utterance, the consecutive interpreter is the quintessential instrumental translator. And that is why those who have hit closer to the traductological nail are the theoreticians of consecutive interpretation. Surprisingly enough, many of the best consecutivist Hydes become uncompromising Jekylls upon stepping into the booth.

\section{Consecutive interpretation}

In CI, the value of $t m+n$ becomes unnatural, which may prevent the retention and reproduction of many propositional and non propositional details. This objective restriction, basically due to the neurophysiological substrate of the retention and recall mechanisms, must be compensated by a professional development of analytical ability, i.e. of the ability to grasp propositional structure and pragmatic intentions. This analytical ability (and not the ability to recall) is the one that, whether interpreting or not, we bring into play in order to understand, to contribute our half of the effort that allows for relevant $L P I / L P C$ identity when we listen to monological discourse or when we read any minimally sophisticated text. More apparently that in any other form of mediation, in CI having understood means, first and foremost, 
having understood structure: a sophisticated line of argumentation permeated by a pragmatic attitude. Structure is, by definition, a metarepresentation based on the lineal comprehension of speech which alone can be stored in long-term memory. Intelligence lies, precisely, in the ability to metarepresent, of putting distant twos together, of identifying the system governing a usually untidy sequence of utterances - not everyone who understands a man's speech can understand the man. This is no longer a "natural" ability: some people are incapable of it. The practitioner - and especially the student - must therefore worry more about having understood than about being able to remember, since one cannot remember what one has not been able to understand.

Why, then, such anxiety and eagerness to remember? Precisely because memory has its own neurophysiological constraints that cannot be controlled cognitively. The consecutive interpreter requires, no doubt, special training that will allow him to overcome or palliate such first-objectual limitations. The most effective instrument, as we know, are the notes, i.e. the graphic representation of certain LPIo clues that make it possible to evoke it in its relevant entirety. An effective instrument, indeed, provided it is used effectively. And there's the rub: a note, as a knot in the handkerchief, is useful only if it does the trick, i.e. if it enables the subject to recall what is relevant, be it the population increase in Asia during the 15th century or a wedding anniversary ${ }^{6}$. The problem with notes never lies with the notes themselves (as it does not lie with the exact nature of the handkerchief or the knot), but with the criterion governing them. This brings us back to the basic ability that an interpreter must boast: the ability to analyse - itself the cornerstone of the ability to understand. To analyse motivations, intentions, arguments, positions, stakes - and not simply the specific LPIs and their verbalizations that speakers resort to in order to communicate "officially" with each other as a function of all of the above ${ }^{7}$. As always, this analysis must develop at either end of a Dvo/DVi combo. It does happen that the interpreter $\mathrm{B}$-and especially the student-B loses sight of the social poles of communication between which he is called upon to mediate. Ontologically, cognitively and chronologically, this is the first reason why notes are taken ineptly. Although there is an additional aspect: the kinetics of note-taking itself. An interpreter who spends all the time with his nose stuck into the pad, doodling rabidly without lifting up his eyes to look at the speaker and at his own future interlocutors, a) misses most of the pragmatic meaning conveyed kinetically by the speaker, b) fails to establish a pragmatically relevant relationship with both speaker and audience, c) prematurely disregards the decisive $E$ of his imminent act of speech, and, most decisively, d) cannot possibly understand effectively: the more attention the interpreter devotes to writing, the less he can spare for understanding and, especially, metarepresenting meaning.

Since due to the unnatural $t m+n$ value, a consecutive interpreter has no way of retaining the phonomorphosyntactic chain (unless, again, he is a trained stenographer, but there are very few of them in the profession), the great trap is always semantic: when the novice interpreter has written down a word or concept and then cannot recall what exactly that word or concept was doing in the original speech, very often he puts together any which utterance to insert them - which normally leads straight into utter nonsense. Since noetic content is not linguistic, notes can be words in either language or in any third one, or in all of them at once, or - deverbalizing the LPIo and transforming Fo into sheer $E$ - in more or less iconic symbols, such as 
arrows; or in totally idiosyncratic marks or any other graphic device... so long as it later helps relevantly to recall noetic content - i.e. to re-apprehend the LPI (already peeled off the vanished $\mathrm{Fo}$ ) and reverbalize it by means of a new $\mathrm{Fi}^{8}$.

Another element that is not to be overlooked, of course, is pragmatics. Notes are only helpful when it comes to noetic content: indeed, there is no reason to "note" anything else. What happens is that, once Fo has vanished from memory, the beginner interpreter (and more than just a few veterans) completely forgets that the speaker was joking, selling or lecturing. In fact, the loss of the pragmatic component reveals a deficient understanding. In other words, if the interpreter has not grasped pragmatic "meaning," he has not understood relevantly, so that in the end LPIo[F]LPCi. And if the problem is that he did understand it, but has now neglected to convey it, then he is no longer relevantly saying what he did understand, so, again LPIo[ $[$ ]LPCi.

Lastly, we have the neurophysiological and cognitive features of memory. But here this model, centred on the social aspects of mediation, has nothing new to contribute.

And there is more: the whole process, is emotively drenched, since the motivation to speak and to understand - let alone the effects of comprehension - proceed from the subject's unconscious. A normal listener (i.e. a listener who is personally - or naturally - interested in understanding what the speaker is trying to say and do by saying) is not only understanding an utterance on-line: he is actively metarepresenting meaning and intentions, incorporating newly processed information into a vast and complex system of presuppositions, constantly checking what he hears against what he knows and expects. A normal hearer activates, therefore, powerful emotive and logic filters sieving input from the speaker: he is a critical interlocutor. Wherein lays the rub: when called upon to interpret (or translate), a student - or, alas!, many a professional mediator - rarely understands speech as a normal interlocutor, i.e. out of a natural motivation governing a host of expectations, naturally producing as a consequence a host of metarepresentations and naturally experiencing thereupon a host of relevant effects. And then he will rarely produce speech as a normal speaker, out of a natural motivation to make himself understood by a specific interlocutor, with a specific intention naturally to produce on him a host of metarepresentations and, thereby, a host of pragmatic effects. If a mediator has no real interest in what is being said or, worse, is stressed, his hermeneutic guard goes to sleep. This is, I suspect, the reason for many - perhaps most - mistakes. And this is the reason that I insist so much in the students' understanding as if personally interested - i.e. in their understanding critically. For this, practice must closely replicate real life communication.

The only way of having them deal in class with a real, flesh-and-blood speaker addressing a real, flesh-and-blood set of interlocutors is to bring in a speaker (another teacher, a student from the same or, perhaps better, another class, or, better still, a total outsider) and have him speak about something that would be genuinely interesting to them. This is the only way that a real-life communication situation can begin to be established. Unless they become emotively involved, unless they really feel interested in the information conveyed by the speaker, students will not listen to him as a producer of coherent meaning but as an utterer of a disconnected string of pieces of information.

Indeed, bereft of a natural motivation to understand or make themselves understood, students will automatically tend to understand modularly, seldom going beyond 
the most basic semantic representations, which will effectively prevent them from producing anything remotely resembling a metarepresentation of meaning globally meant. This lack of critical analysis, as I pointed out, is the main culprit of comprehension and production mistakes. Even if there should be none, the student will produce at best a string of propositions that may, if serendipitously recalled and strung back together, add up to a cracked mirror of the original, but will never coalesce as the verbalization of a structured verbalization of a structured sequence of percepts.

\section{A practical example}

I take part as an external juror at the graduation exams of several European schools. At one of them, English speeches are delivered by a teacher notorious for his sense of humour, whom all students know. On this particular occasion, he spoke about the difference between British colonialism and that of Belgium, France, Germany, Italy, the Netherlands and Spain. Here is, in a nutshell, the speaker's main intended sense: colonialism is bad, but British colonialism was better than most. Nowadays, the Empire long gone, most of Britain's overseas territories cannot be considered colonies. This sense was conveyed with typical irony - both semantic and paralinguistic - that had the panel roaring with laughter. Let me exhume from long-term memory three passages that proved particularly relevant when interpreted into French by four successive students: 1) At the time of its peaceful independence (the violence that ensued was internecine and Britain had warned against it), India had 65,000 kms of efficient railroads - Algeria and Morocco had camels. 2) In 1982, Margaret Thatcher went all out to free a handful of remote people holding British passports from the grip of an Argentine military dictator. 3) Gibraltar looks pretty much like a small English village of the sixties, with its red letter boxes, smiling bobbies and quaint pubs called The Lion's Head or The Queen's Arms, serving tepid and hopelessly flat beer.

\section{a) A pragmatic non-starter}

None of the four students in question laughed as they took notes: it was clear that they were not getting the speaker's point. Not surprisingly, none of them spoke as if any humour were intended (and I am not referring to noetic content - although all of the semantic humour did vanish - but to paralinguistic or kinetics: none sounded or looked like they were saying anything funny).

\section{b) A pragmatic catastrophe}

Student b turned "the grip of an Argentine military dictatorship" into "the grip of the Argentines" - a rather suicidal booboo if you consider that one of the jurors - your's truly - was Argentine (the student did not know, but that is no excuse: "Argentine military dictator" had obviously been chosen intentionally by the speaker in order not to blame the whole of the Argentine people). Again, the student was restituting noetic content without any notion of pragmatic meaning.

\section{c) Modular, incoherent comprehension}

Once the listener has missed the speaker's pragmatic intention, comprehension of noetic content becomes difficult. Witness what became of the Algerian and Moroccan 
camels in the lips of one of the students: "At the end of colonialism, India had 65,000 kms of efficient railroads, while Algeria and Morocco had canoes." Gondolas in the Sahara? The student was no moron, yet he produced one of the most moronic contresens in my recent memory. How come? My guess is that he did understand "camels" but ran into trouble upon striving to decipher his notes. Still, how is it that he did not think of saying simply "India had $65.000 \mathrm{kms}$ of efficient railroads, while Algeria and Morocco had zilch!" which would have done - if not as effectively - the pragmatic trick? Again, because the intelligence service had taken a rest: the student had no notion of what the speaker before him and now he himself were saying: the graphic resemblance between "camel" and "canoe" or "chameaux" and "canoës" superseded the differences between the referents in context. Another pragmatic point that was completely lost upon the student was the English stab at France.

\section{d) Total inability to activate relevant schemata, frames, scenes and scenarios}

All four students had labouriously taken down Gibraltar's picturesque features, down to the pubs' quintessentially English names. Since the names had been jotted down in haste, all spent an inordinate amount of time trying to put them together again - which wreaked pragmatic havoc, since the effect upon the audience was one of impatience verging on exasperation. None of them realized that a) the names were merely illustrative, that therefore b) they could be omitted altogether or that c) they could be substituted. But what was more glaring was their inability to make head or tail of the tepid and hopelessly flat beer: this school was in Belgium and all four students were Belgian! A sheer GB English village 60's ought to have sufficed: the illustrative details would have been activated automatically: if not the red letter boxes, then perhaps the red telephone booths (as another student said), the bobies (whether smiling or not), the quaint pubs (with or without names) and, I bet, most inevitably, the tepid flat beer. But no: the students proceeded with puzzlement to peruse their string of knots in the handkerchief. An awareness of the model above, I submit, might have helped them do a better job.

\section{A gleam of hope}

There were other students, of course, who did better, even brilliantly. Two come particularly to mind who had managed brilliantly with a similar speech by the same speaker. One of them had even found it difficult to take notes because, together with the rest of the audience, she was shaking with laughter. I am proud to have offered them both their first contracts ever a few weeks later.

\section{NOTES}

1. García Landa's unpublished experiments reveal that such LPs are respectively produced and comprehended every 250 milliseconds or so. His model basically treats speech percepts as a complex "space" consisting, as I understand it, of the immediate top-down processing of a series of such "mini" percepts.

2. It is not certain whether registers constitute a system.

3. Of course, this emotive package can be developed with vital experience and the development of the hermeneutic package: poets that we used to like become trivial or awkward, others suddenly reveal themselves to us after years of intermittent readings.

4. I know whereof I speak: I am a chief interpreter. 
5. For the reader unfamiliar with relevance theory, may I explain that, according to Sperber and Wilson (1986/1995), utterances can be used as representations in two basically different ways: 1) an utterance may propositionally resemble a state of affairs in the world, in which case language is used descriptively, and 2) an utterance may propositionally resemble another utterance, in which case language is used interpretively. In the first case, the utterance describes a (possible) state of affairs in the world, in the second - it reproduces, as it were, the propositional content of a previous utterance, or, if you wish, of a previous description of a (possible) state of affairs in the world.

6. A note, like a knot, must activate a whole gamut of knowledge and representations, of frames and scenarios: I am reminded of my anniversary and, without any need for additional knots, I remember that I must buy flowers, that my proprietor has told me she liked very much that ring that she saw in this shop, that I have to reserve a table at such restaurant, etc. I know interpreters who write down even the final "thank you"!

7. As Jones (1998: 5 and foll.) rightly points out, the (good) interpreter is engaged in active listening, much more intensive and concentrated than any other interlocutor, even if the latter is much more interested in the communication than the interpreter himself. The interpreter's role as a mediator forces him to prove publicly and on the spot that he has understood, analysed and assimilated thoroughly the original Dvo (and not only its semantic vehicle), and, besides, that he has been able aptly to synthesize it.

8. This "deverbalization" is the theoretical basis of the interpretive theory, born, precisely out of the empirical experience of consecutive conference interpreters. This, in turn, explains both the interpretivists, fundamental hit and their decisive miss when it comes to the non-propositional aspects of an LPI and the aesthetic features of Fo.

\section{REFERENCES}

García LAnda, Mariano (2001): Teoría general de la traducción, Vertere, Monográficos de la revista Hermeneus núm. 3-2001, Soria.

Jones, Roderic (1998): Conference Interpreting Explained, St. Jerome Publishing, Manchester.

Reiss, Katharina and Vermeer, Hans J. (1991): Fundamentos para una teoría funcional de la traducción, Akal Ediciones, Madrid.

Sperber, Dan and Wilson, Deirdre (1986/1995): Relevance. Communication and Cognition, Blackwell, Oxford/Cambridge. 